\title{
Research of Economic Performance Evaluation Indicators of Energy-loss Thermal Power Unit Based on Controllable Parameter Change
}

\author{
Donghui Song ${ }^{1,2}$ \\ ${ }^{1}$ Engineering Thermophysics, \\ North China Electric Power University, \\ Jilin, China \\ ${ }^{2}$ Engineering Thermophysics, \\ Northeast Dianli University, \\ Jilin, China
}

\begin{abstract}
Energy-loss analysis refers to analyzing influence of some parameters deviated from targeted working condition on unit thermal economy during unit operation [1-3]. Coal consumption analysis aiming at thermal power unit controllable parameter changes aims at determining influence extent of controllable parameters on unit performance, thereby providing scientific basis for improving economic operation level of the unit. It acts as one of basic theory work tasks necessary for realizing energy saving and consumption reduction of thermal power unit [4, 5]. Model of coal consumption deviation calculation caused by thermal power unit important operating parameters deviated from the target value is proposed through the study of relation between important controllable operating parameter change in thermal power generating unit and coal consumption. The model can be applied to on-line monitoring system of unit operation thermal economy. "Performance factor" is adopted to evaluate advantages and disadvantages of thermal power unit performance. Concepts of operational performance factor and maintenance performance factor are introduced for distinguishing factors affecting unit operation from factors affecting maintenance. Meanwhile, concepts of "energy loss factor," "relative energy loss rate," etc., are proposed in order to further diagnose actual reason of unit energy loss and provide guidance for operation.
\end{abstract}

Keywords-controllable parameter; economic operation; energy loss factor

\section{INTRODUCTION}

Electricity production sector in China has always followed "power supply coal consumption rate" as indicator for comprehensively evaluating performance advantages and disadvantages of coal-fired unit for long term. Values of both "coal consumption rate" or "thermal consumption rate" are related with subjective factors of unit maintenance quality, operation management level, etc. on one hand, they are changed with changes in equipment healthy state, design level, load, environment temperature, coal category and other objective factors. Therefore, when coal consumption rate or heat consumption rate is adopted for evaluating unit performance, subjective factors and objective factors cannot be distinguished [6]. Therefore, the author proposes "performance factor" as the performance evaluation indicator of the unit. It can be used for distinguishing subjective factors from objective factors affecting unit performance. Unit operation economy can be scientifically reflected. Concept of "energy-loss factor" is proposed in order to realize energy loss analysis and operation guidance on the unit, thereby quantitatively analyzing various losses in unit operation, and providing scientific basis for improving economic operation level of the unit. The model also can be applied to thermal economy online monitoring system of unit operation, therefore, research of controllable parameters is very important for thermal power unit economic performance influence [7].

\section{PERFORMANCE FACTOR CONCEPT}

When external load, coal category, environmental temperature and other objective conditions are given in a given period aiming at ordinary condensing unit, the consumed fuel is under the assumption that the unit is always operated under the best state. Since some equipment always suffers from fault or defect at certain degrees during actual operation process, the consumption is also affected by operator operation level, responsibility and other subjective factors, thereby it is difficult to ensure that the unit can be always operated under the best state.

\section{MODEL}

Coal consumption deviation calculation model caused by thermal power unit operating parameters deviated from target value is shown as follows: variable quantity $\mathrm{A}=$ variable quantity $\mathrm{B}^{*} \mathrm{C}$.

Wherein, variable quantity A refers to coal consumption variable quantity when one operating parameter is deviated from target value. Positive value represents coal consumption increase, and negative value represents coal consumption reduction. Variable quantity B refers to relative variable quantity of economic indicator when one operating parameters is deviated from target value, it may be relative efficiency variable quantity, such as boiler efficiency, unit efficiency, etc., which also can be relative variable quantity of unit thermal consumption rate caused by the parameter deviation. When selective economy is improved according to concrete condition based on the principle of simplifying consumption, the value is nega- 
tive, $\mathrm{C}$ refers to power generating standard coal consumption rate.

\section{ENERGY LOSS FACTOR}

Performance factor of the unit refers to general consumption of unit operation quality and equipment healthy state. It has important function for improving scientific feature of operation assessment. However, performance factor itself cannot clearly describe parts of the unit with improper operation and equipment with defects. Therefore, we further propose the concepts of "energy loss factor," "local energy loss factor," etc. Key reasons affecting unit economy can be quantitatively analyzed and diagnosed. Relation between unit performance factor and energy loss factor can be discussed. Unit performance factor is consistent with energy loss factor, the former reflected the ratio between unit actual fuel consumption and best fuel consumption, the later reflects ratio between fuel increase caused by unit energy loss and best fuel consumption. Unit energy loss factor is larger, corresponding performance factor is larger, and obviously unit operating quality and equipment performance are poor. Relation between unit energy loss factor and all energy losses is observed currently since fuel consumption increase caused by total unit energy loss is the sum of fuel consumption increase respectively caused by various energy losses.

\section{OPERATION PERFORMANCE FACTOR AND MAINTENANCE PERFORMANCE FACTOR}

Performance factor of the unit reflects unit maintenance quality, equipment health status, operation level of operating personnel and other comprehensive information. If composition in elements affecting performance factors about operation and maintenance can be distinguished, the process has real significance for guiding safe and economic operation of unit. Influence of equipment healthy state on unit performance is not considered at present, namely all operation controllable parameters of current unit are kept in the best state when actual equipment is in the healthy state.

\section{CALCULATION OF OPTIMUM FUEL CONSUMPTION}

Possible operating conditions of the unit include normal operation, startup, shut down, load lifting and other processes within certain period of time. Therefore, best fuel consumption of the unit should be determined respectively and considered comprehensively. Since load lifting belongs to a transient process, the calculation is very complicated, therefore transient process is discrete, and divided into several small steady-state processes, namely quasi-steady state processes. Operating condition of the unit can be divided into steady-state operating conditions and start-stop working condition for treatment.

\section{A. Determination of Best Fuel Consumption during Stable Operation of Unit}

When the external load, coal category, environment conditions and other objective factors of unit have been determined in given period of time. It is required that each instantaneous unit can be in the best health status and operation status during operation time in order to minimize fuel consumption of the unit, namely reaching the best fuel consumption. Unit load in certain period of time within the operation time section should correspond to the best power supply coal consumption rate.

\section{B. Determination of Best Fuel Consumption in Unit Startup and Stop Process}

Unit start up and stop process has strong transient process; therefore calculation method in stable operation working condition is not applicable to start-up and stop process. Therefore, the proposed simplified calculation method is adopted in the paper, the start-up and stop processes are divided into several stages for calculating energy loss coefficient in each stage. Then, total fuel consumption of the start-up and stop process can be obtained according to sum of best continued time at all stages. Only ignition preparation before the equipment and minimum consumed fuel during ignition, rotation and merging process are considered in the start-up process. Stop operation stage of the unit after load removal is considered only. Best fuel consumption at load lifting stage during start-up process and load decreasing stage during shutdown process is calculated by adopting calculation method at steady-state operating condition, and the time units should be divided more densely.

In summary, best fuel consumption in given time can be obtained on the basis of obtaining unit steady-state operating conditions and startup-shutdown working condition.

\section{LOSS DIFFERENTIAL ANALYSIS CAUSED BY VARIOUS} FACTORS

\section{A. Energy Loss Difference Caused by Main Steam Pressure Changes}

High-parameter and high-capacity unit during actual field operation is provided with two modes of sliding pressure operation and constant pressure operation at different load stages aiming at keeping the best operation economic performance at both high and low load stages. High pressure valve keeps one valve level during sliding pressure operation. Unit load is changed with main stream pressure change. When the main steam pressure is changed from $\mathrm{p}_{\mathrm{a}}$ to $\mathrm{p}_{\mathrm{b}}$ during steam turbine load operation, ideal curve of all parameter changes is shown in Figure 1.

\section{B. Loss Difference Caused by Main Steam Temperature Change}

Main steam temperature refers to steam temperature in front of main throttle valve of steam turbine. Main steam temperature is an important indicator to affect cycle efficiency. Main steam temperature may be possibly 
changed in actual operation of unit. Influence of main stream temperature change on unit economy is more serious corresponding o influence of main stream pressure change on unit economy.

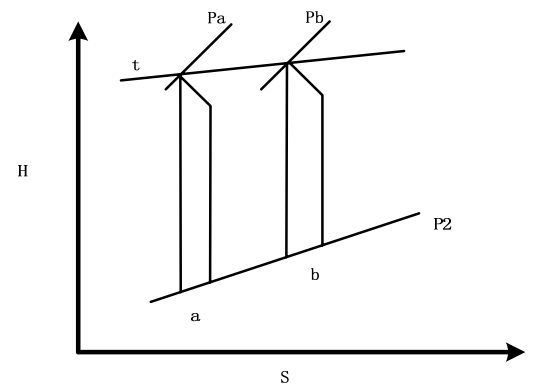

Figure 1 . The constant temperature and pressure change for enthalpy entropy.

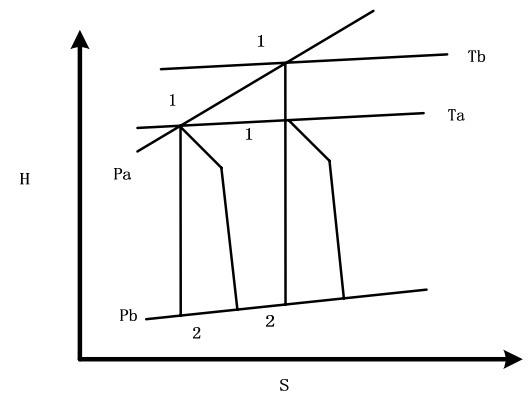

Figure 2. The constant pressure and temperature change for enthalpy entropy.

When the main steam temperature $t_{a}$ is changed to $t_{b}$ during unit operation and ideal curve of all parameter changes is shown in the Figure 2. Main steam temperature increase is equivalent to increase of heat efficiency due to improvement of unit heating average temperature.

\section{DETERMINATION OF ACTUAL FUEL CONSUMPTION FOR THE UNIT}

Fuel actually consumed by the unit is higher than the best fuel consumption due to many reasons in operation and maintenance in actual operation process. Main reasons include the follows that unit equipment has defect, the operation personnel has low technical level and responsibility, the equipment is started and stopped not in line with the best startup and stopping mode, and maintenance quality is poor. In recent years, large units are provided with advanced distributed control system (DCS), which lays foundation for us to realize online measurement of unit performance parameters with rapid development of automation level, measurement technique and computer technique in thermal power plant. Fuel consumption of unit can be calculated in real time through analysis and calculation of primary measurement parameters, meanwhile operation parameters of all equipment and units are analyzed for discovering the reasons affecting performance factor deviation. Theoretically, online measurement method is divided into positive balance and counter-balance. Since flow capacity and thermal power of coal in the furnace are lack of mature technology for online measurement at present, thereby limiting use of positive balance method, therefore application of positive balance method is limited, and counter-balance method is generally adopted.

The basic method of counter-balance method: cycle thermal consumption rate, boiler efficiency and factory electricity consumption rate in certain time can be respectively obtained through calculation and analysis of primary parameters, thereby calculating power supply coal consumption rate of the unit, and accumulating fuel consumed by the unit at different periods of time during the observation period.

\section{ENERGY LOSS FACTOR}

Performance factor of the unit is general expression of unit operation quality and equipment healthy state, which has important function for improving scientific feature of operation assessment. However, improper operation parts of the unit or equipment with defects cannot be clearly specified on the performance factory itself. Therefore, we further proposed unit "energy loss factory," "local energy loss factory" and other concepts, quantitatively analyzing and diagnosing key reasons affecting unit economy, and relationship between unit performance factor and energy loss factor is discussed. Performance factor of the unit is consistent with energy loss factor, the former reflects the ratio between actual fuel consumption of the unit and the optimum fuel consumption, the later reflects the ratio between fuel increase caused by unit energy loss and best fuel consumption. Unit energy loss factor is larger, corresponding performance factor is larger, and unit operating quality and equipment performance are poor obviously. Relation between unit energy loss factor and all energy losses is observed currently since fuel consumption increase caused by total unit energy loss is the sum of fuel consumption increase respectively caused by various energy losses.

\section{APPLICATION EXAMPLE OF CONSUMPTION DIFFERENCE ANALYSIS}

Consumption different analysis refers to influence of some parameter deviated from target working condition on unit thermal economy during unit operation. Consumption difference analysis method refers to comparison between unit operation actual value and unit benchmark value. Coal consumption rate of the unit can be calculated, and influence of operation parameter change on unit economy can be obtained. Main operation parameter loss difference analysis summary table of thermal unit is shown in the following Table I.

One domestic condensing unit is adopted as an example for calculating all indicators thereof in $8 \mathrm{~h}$ in order to further clarify implementation method of unit performance factor and energy loss factor. The unit is in the stable operation working condition in the period of time without startup and stop phenomena. Meanwhile, it is 
assumed that the coal quality in the furnace is more stable; environment temperature is also treated as constant in order to further simplify calculation. The figure shows load after discrete treatment in certain time period (30min is regarded as a time unit). Value of some point in the figure represents average value of the first half year in certain given time. Ordinate refers to generator active power MV. Performance simulation software is respectively adopted and calculated for obtaining the best power supply coal consumption rate and operation best power supply coal consumption rate of the unit in all time periods. Meanwhile, on-line data and coal experiment data measured by the computer monitoring system can be utilized for calculating actual coal consumption rate of the unit in all time periods (Figure 3).

TABLE I. THE DIFFERENCE CONSUMPTION ANALYSIS OF MAIN OPERATION PARAMETERS FOR THERMAL POWER UNIT.

\begin{tabular}{|l|c|c|c|}
\hline \multirow{2}{*}{ Parameter Name } & \multicolumn{3}{|c|}{$300 \mathrm{MW}$} \\
\cline { 2 - 4 } & $\begin{array}{c}\text { Reference } \\
\text { value }\end{array}$ & $\begin{array}{c}\text { Actual } \\
\text { value }\end{array}$ & Consumption \\
\hline $\begin{array}{l}\text { Exhaust tempera- } \\
\text { ture }\end{array}$ & 127.45 & 124.96 & 0.82 \\
\hline Exhaust oxygen & 3.42 & 3.6 & -0.27 \\
\hline $\begin{array}{l}\text { Fly ash carbon } \\
\text { content }\end{array}$ & 3.02 & 5.43 & 0.62 \\
\hline $\begin{array}{l}\text { Main steam } \\
\text { pressure }\end{array}$ & 15.9 & 17.23 & 0.79 \\
\hline $\begin{array}{l}\text { Main steam } \\
\text { temperature }\end{array}$ & 541 & 530.96 & 0.03 \\
\hline
\end{tabular}

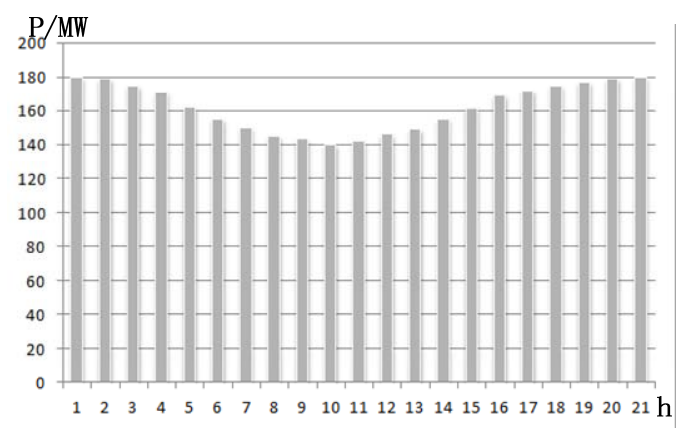

Figure 3. The load curve for the unit for one day.

\section{CONCLUSIONS}

In the paper, unit operation economy within certain period of time can be evaluated by "performance factor." Compared with traditional power supply coal consumption rate, Objective and subjective factors affecting unit economy can be comprehensively considered; health state and operation quality unit equipment can be scientifically reflected. Changes of coal consumption indicator can embody economic performance of unit operation, intact degree of unit internal mechanical state, and other information. Energy loss can be analyzed for power thermal plant, influence of operating parameters deviated from target value on power plant coal consumption can be quantitatively reflected, thereby timely guiding operator adjustment and operation mode. Unit can be operated under the best working condition, which is beneficial for improving thermal economy of thermal power plant operation. Meanwhile, concepts of unit energy loss factor, local energy loss factor and relative energy loss rate are further proposed in order to further examine influence of various energy losses on unit overall performance, thereby the concepts have important function on guiding operators in improving unit economy. Various performance analysis methods refer to dynamic analysis on some load point. Various performance indicators and calculation method proposed in the paper refer to dynamic performance analysis with consideration of various objective and subjective factors within certain period of time aiming at the unit. Therefore, the method has better application performance and scientific feature in the aspects of operation quality assessment, operation and maintenance guidance.

\section{REFERENCES}

[1] Yang Yong-ping, Guo Xi-yan, Wang Ning-ling, Power generation from pulverized coal in China [J]. Energy, 35(11), pp. 4336-4348, 2010.

[2] Yang Yong-ping, Yang Kun, Theory of energy conservation potential diagnosis for a coal fired unit and its application [J]. Proceedings of the CSEE, 18(2), pp. 131-134, 1998.

[3] Hu Hong-hua, Huang Ting-hui, Ai Weiguo, et al., Study a novel dynamic clustering algorithm and its application in fuzzy modeling for thermal processes [J]. China Electric Power, 37(9), pp. 22-25, 2004.

[4] Hong Jun, Cui Yan-feng, Bi Xiao-long, et al., A unit on-line operation optimization system and determination of real-time optimum operation mode [J]. Automation of Electric Power Systems, 31(6), pp. 86-90, 2007.

[5] Wang Hui-jie, Zhang Chun-fa, Song Zhi-ping, Sensitive analysis of energy consumption of operating parameters for coal-fired unit [J]. Proceedings of the CSEE, 28(29), pp. 6-10, 2008.

[6] Wang Ning-ling, Theoretical research on data mining-based energysaving diagnosis and optimization for large coal-fired power units [D]. North China Electric Power University, Beijing, 2011.

[7] Niu Cheng-lin, Liu Ji-zhen, Ma Yong-guang, et al., Determination of optimal oxygen content based on the incremental data mining technique [J]. Proceedings of the CSEE, 29(35), pp. 29-34, 2009. 